\title{
DOES COGNITIVE CAPACITY INTERFERE WITH THE OUTCOME OF OBERLIN TRANSFER?
}

\section{A CAPACIDADE COGNITIVA INTERFERE NO RESULTTADO DA CIRURGIA DE OBERLIN?}

\author{
Fernando Antonio Silva de Azevedo Filho ${ }^{1}$, William Zarza Santos ${ }^{1}$, Thomaz Gê de Oliveira ${ }^{1}$, Yussef ali Abdouni ${ }^{1}$, \\ antonio Carlos da Costa ${ }^{1}$, Patrícia Maria de Moraes Barros Fucs ${ }^{1}$
}

1. Irmandade da Santa Casa de Misericórdia de São Paulo, Department of Orthopaedics and Traumatology, São Paulo, SP, Brazil.

\section{ABSTRACT}

Objective: To determine the relationship between the functional outcome achieved following Oberlin transfer, the cognitive level of the patient, and the time elapsed between the trauma event and surgery. Methods: Eighteen patients with a traumatic injury to the brachial plexus (C5-C6 and C5-C7) were evaluated. Seventeen (94.4\%) patients were males and one (5.6\%) was female, with a mean age of 29.5 years (range 17-46 years). We evaluated the active range of motion, elbow flexion strength, and Disabilities of the Arm, Shoulder and Hand (DASH) and determined the correlation between the procedural outcome and the patient's cognitive level, as assessed by the Mini-Mental State Exam (MMSE). Results: We found statistically significant correlations between the MMSE scale and strength recovery $(84.4 \%, p<0.001)$, which was classified as excellent, and between the MMSE and British Medical Research Council (BMRC) scales (78.4\%, p>0.001), which classified cognitive level as good. Conclusions: We found a positive correlation between cognitive capacity and functional outcome of patients submitted to Oberlin surgery. The time elapsed between trauma and the surgical procedure showed an inversely proportional correlation with the strength of recovery. Level of Evidence II, Retrospective Study.

Keywords: Brachial Plexus. Nerve Transfer. Cognition. Ulnar nerve. Musculocutaneous nerve

\section{RESUMO}

Objetivo: Determinar a relação entre o resultado funcional obtido com a cirurgia de Oberlin, o nível cognitivo do paciente e com o tempo decorrido entre o trauma e a cirurgia. Métodos: Foram analisados dezoito pacientes, sendo 17 homens (94,4\%) e uma mulher (5,6\%), com idade média de 29,5 anos (17 a 46 anos), com lesão traumática alta do plexo braquial (C5-C6 e C5-C7). Avaliamos a amplitude de movimento ativa, a força muscular de flexão do cotovelo e o questionário DASH (Disabilities of the Arm, Shoulder and Hand) e determinamos a correlação entre o resultado obtido e o nível cognitivo do paciente, avaliado pelo Mini Exame do Estado Mental (MEEM). Resultados: Observamos correlações de significância estatística entre MEEM e recuperação de força (84,4\%, $p<0,001)$, classificada como ótima; MEEM e BMRC - British Medical Research Council (78,4\%, p>0,001), classificada como boa. Conclusões: Verificamos correlação positiva entre a capacidade cognitiva e os resultados funcionais dos pacientes submetidos à cirurgia de Oberlin. O tempo decorrido entre o trauma e o procedimento cirúrgico apresenta uma relação inversamente proporcional com a recuperação da força. Nível de Evidencia II, Estudo retrospectivo.

Descritores: Plexo Braquial. Transferência de Nervo. Cognição. Nervo Ulnar. Nervo Musculocutâneo.

Citation: Azevedo Filho FAS, Santos WZ, Oliveira TG, Abdouni YA, Costa AC, Fucs PMMB. Does cognitive capacity interfere with the outcome of oberlin transfer? Acta Ortop Bras. [online]. 2018;26(6):394-6. Available from URL: http://www.scielo.br/aob.

\section{INTRODUCTION}

The incidence and severity of the brachial plexus injury have both been increasing worldwide. Upper trunk impairment results in significant disability, with loss of shoulder function (abduction of the shoulder and external rotation), elbow flexion, and supination of the forearm. For these patients the priority is to restore elbow function, followed by abduction and external rotation of the shoulder. ${ }^{1-10}$ Neurotization techniques have significantly improved the outcome of surgical treatment of upper brachial plexus injuries. ${ }^{11}$ Recent studies have shown superior results with regard to elbow flexion when ulnar nerve fascicles are used as a donor, ${ }^{1,5}$ in a technique described by Oberlin, ${ }^{6}$ which uses a predominantly motor fascicle of the ulnar nerve that is transferred to the motor branch of the biceps. The satisfactory results obtained with this technique are related to the fact that nerve suturing is done to a healthy area, is single-threaded and at a short distance from the target muscle, and relies on the use of a well-vascularized nerve for the transfer..$^{1,5,11}$ It is a procedure that causes minimal morbidity to the donor site. $^{3}$

All authors declare no potential conflict of interest related to this article.

Work conducted at Irmandade da Santa Casa de Misericórdia de São Paulo, São Paulo, SP, Brazil.

Correspondence: Fernando Antonio Silva de Azevedo Filho. Alameda Pádua, 470, AP 2402, Salvador, BA, Brazil. CEP: 41830-480. azevedofilho@gmail.com 
Brachial plexus injury leads to central functional remodeling, with attention being focused on the sensorimotor areas of the brain. ${ }^{12}$ Not only age but also surgical repair techniques are of the utmost importance for sensitivity recovery following the repair of peripheral nerve injury. If regenerating axons are misdirected, a reorganization or other adaptive processes at the level of the somatosensory cerebral cortex becomes necessary. Such processes are believed to depend on the patient's cognitive capacity. ${ }^{13}$ There is likely to be a positive correlation between cognitive ability and the outcome of functional sensitivity after peripheral nerves have been repaired, which suggests that variations in such factors may help to explain result variability. ${ }^{13,14}$ The main goal of this study is to determine the relationship between the functional outcome obtained with Oberlin transfer and the patient's cognitive level, and the time elapsed between trauma and surgery.

\section{MATERIALS AND METHODS}

We conducted a cross-sectional study with patients from the Hand Surgery and Microsurgery Outpatient Clinic at Universitary Hospital, São Paulo, Brazil. The study was approved by the local institutional ethics review board (approval number: 2.550.903) and all patients signed an informed consent form before inclusion in the study.

We included patients with traumatic injuries to the brachial plexus at $\mathrm{C} 5-\mathrm{C} 6$ and $\mathrm{C} 5-\mathrm{C} 6-\mathrm{C} 7$ levels, above 15 years of age, undergoing Oberlin transfer, either associated or not with concomitant procedures to the brachial plexus (reconstructions with grafting, intraplexal or extraplexal neurotizations such as: transfer of the accessory nerve to the suprascapular nerve, from the motor branch of the triceps muscle to the axillary nerve) and followed them up postoperatively for a period of at least six months. Patients diagnosed with obstetric paralysis, pediatric patients $s_{1}$ and patients with lower or total brachial plexus injuries were excluded from the study.

Eighteen patients were therefore evaluated, of whom 17 (94.4\%) were males and one was female (5.6\%), with a mean age of 29.5 years (1746 years). With regard to the level of the injury, 13 patients presented C5-C6 injuries (72.2\%) whereas five of them had C5-C7 injuries (27.8\%). The time elapsed between trauma and the surgical procedure ranged from three to 17 months, with an average of 9.2 months.

We evaluated the active range of motion, elbow flexion strength, and DASH (Disabilities of the Arm, Shoulder and Hand) ${ }^{15}$ questionnaire and then determined the correlation between the outcome obtained and the patient's cognitive level, as assessed by the Mini-Mental State Examination (MMSE). ${ }^{16}$ We also correlated the time between injury and surgery with the functional outcome.

Goniometry was used to define the range of free active motion. With the patient standing, the goniometer was placed in the sagittal plane with its center on the elbow joint; then, starting from the maximum extension position, the patient was instructed to perform maximum flexion, with the obtained value being expressed in degrees.

Muscle strength was measured during elbow flexion in two ways: by using the British Medical Research Council (BMRC) scale or a dynamometer.

For the first evaluation, the patient was instructed to remain in the seated position, with an upright trunk to avoid compensatory movements during the test. The examiner stabilized the patient's shoulder, providing the necessary support. The strength was graded as M0 when no sign of muscle contraction was observed; M1, muscle fasciculation; M2, when strength did not overcome the force of gravity; M3, when it overcame gravity, but did not overcome a resistance; $\mathrm{M} 4$, when it overcame the resistance, but was not normal; M5, normal strength. A lower than M3 result was considered poor and the patient did not undergo the dynamometry test.

The evaluation using the dynamometer followed the guidelines of the American Society of Exercise Physiologists (ASEP), as described by Brown. ${ }^{17}$ Elbow flexion strength was measured in kilograms (kgf) by using a Lafayette ${ }^{\circledR}$ Manual Muscle Test (MMT) model 01163 comprised of two rigid adjustable straps, with one end fixed to the ground by a suction cup and the other end in the patient's hand. The patient remained seated and kept the elbow at a $90^{\circ}$ angle close to the body while keeping the forearm in a supinated position. The device has been set to adapt to the patient's height. We took three consecutive measurements, with an average interval of 30 seconds between them, with each contraction lasting five seconds. The mean of the three measurements was then considered for analysis. With the lack of knowledge of the degree of muscular strength of the limb involved before the injury, the value obtained was compared with the contralateral side, muscle strength M5, which is closest to what is considered normal and then the percentage of force recovery was determined. The strength of the contralateral side was assessed in the same way as was the strength of the affected limb. The collected data were stored with the aid of Windows Excel, and then compared and analyzed by using statistical software (SPSS V20 for Windows). We used a significance level of 0.05 (5\%) in our study, and constructed all the confidence intervals with a 95\% statistical confidence level. Pearson's correlation was used to measure the degree of relationship between all the quantitative variables and to validate the correlations, the Correlation Test was used.

The correlation ranged from -1 to 1 , but in order to facilitate reading and/or understanding, the values were transformed into percentages: values between $0 \%$ and $20 \%$ were considered as very poor; between $20 \%$ and $40 \%$ as poor; between $40 \%$ and $60 \%$ as fair; between $60 \%$ and $80 \%$ as good; and between $80 \%$ and $100 \%$ as excellent.

\section{RESULTS}

When comparing the time interval between trauma and surgery with the BMRC scores and strength recovery, we found negative and inversely proportional correlations (-90.4\%, $p<0.001$, excellent correlation; -69.9, $p=0.001$, good correlation), respectively. We also found a negative correlation between DASH and BMRC $(-67.0 \%, p=0.002)$ and between DASH and strength recovery $(-64.4 \%, p=0.004)$. (Table 1)

We also found statistically significant correlations between the MMSE scale and strength recovery (84.4\%, p <0.001), which was classified as excellent; between the MMSE and BMRC scales $(78.4 \%$, $p>0.001)$, classified as good, and a fair correlation between the MMSE and active range of motion (AROM) scales (47.8\%, $p<0.045)$. In comparing MMSE and DASH, a fair relationship, albeit with no statistical significance, was observed (-43.0\%, p 0.075). (Table 1)

\section{DISCUSSION}

Brachial plexus injury is a severe trauma to the peripheral nervous system, which can cause central remodeling, as revealed by functional $\mathrm{MRI}$ (magnetic resonance imaging). However, this remodeling is

Table 1. Correlation of Quantitative Variables.

\begin{tabular}{|c|c|c|c|c|c|c|c|}
\hline & Age & \begin{tabular}{|c|} 
Time \\
since \\
Trauma \\
\end{tabular} & AROM & BMRC & $\begin{array}{l}\text { Strength } \\
\text { Recovery }\end{array}$ & DASH \\
\hline \multirow{2}{*}{$\begin{array}{c}\text { Time Interval } \\
\text { between Trauma } \\
\text { x Surgery } \\
\end{array}$} & Corr (r) & $47.1 \%$ & & & & & \\
\hline & P-value & 0.049 & & & & & \\
\hline \multirow{2}{*}{ AROM } & Corr $(r)$ & $-27.2 \%$ & $-61.8 \%$ & & & & \\
\hline & P-value & 0.274 & 0.006 & & & & \\
\hline \multirow{2}{*}{ BMRC } & Corr (r) & $-37.1 \%$ & $-90.4 \%$ & $69.3 \%$ & & & \\
\hline & P-value & 0.129 & $<0.001$ & 0.001 & & & \\
\hline \multirow{2}{*}{$\begin{array}{l}\text { Strength } \\
\text { Recovery }\end{array}$} & Corr (r) & $-27.0 \%$ & $-69.9 \%$ & $72.1 \%$ & $89.3 \%$ & & \\
\hline & P-value & 0.278 & 0.001 & 0.001 & $<0.001$ & & \\
\hline \multirow{2}{*}{ DASH } & Corr (r) & $16.1 \%$ & $57.4 \%$ & $-41.0 \%$ & $-67.0 \%$ & $-64.4 \%$ & \\
\hline & P-value & 0.524 & 0.013 & 0.091 & 0.002 & 0.004 & \\
\hline \multirow{2}{*}{ MMSE } & Corr (r) & $-33.7 \%$ & $-56.3 \%$ & $47.8 \%$ & $78.4 \%$ & $84.4 \%$ & $-43.0 \%$ \\
\hline & P-value & 0.171 & 0.015 & 0.045 & $<0.001$ & $<0.001$ & 0.075 \\
\hline
\end{tabular}

Corr (r)- Correlation. 
mainly restricted to the somatosensory cortex. The exact mechanism remains unknown. Several authors ${ }^{13,14,18}$ have related the results from peripheral nerve injury repair with the patients' cognitive capacity. Rozén et al..$^{15}$ described the correlation between restoring functional sensitivity with the cognitive capacity of patients undergoing nerve repair in the forearm. This result is related to the brain's capacity for remodeling and adapting to new functional demands. Boender et al., ${ }^{16}$ in undertaking a prospective multicenter study, found no association between cognitive capacity and sensory recovery, or that it was probably not as strong as suggested in previous retrospective studies. The cognitive function reflects a set of processes and activities that are used in perceiving, thinking and employing these processes not only in sentence comprehension, for instance, but also in object recognition, touch perception and spatial orientation..$^{13}$ There is reason to believe that the brain's ability to understand, use and adapt to cortical reorganization after nerve repair may reflect the individual's cognitive capacity. ${ }^{14}$

The positive correlations found in the study may be related to a better understanding, by the patient, of the treatment used. Communication and an excellent physician-patient relationship are of the utmost importance for a good adherence to the proposed treatment. Such adherence can be understood as the degree of agreement between the guidance received (relative to postoperative care, attendance at follow-up, and rehabilitation) and the patient's behavior. Numerous factors can interfere with the adherence process and consequently the desired outcome. Patient-related factors that can interfere with the adherence process may be related to biosocial traits, such as schooling, socioeconomic level, occupation, marital status, religion, health beliefs, life habits, and cultural aspects.

The patient must be an active agent throughout the process, and have a wish to seek to improve and rehabilitate those functions that have been lost or impaired by the trauma. A variety of combinations of therapeutic procedures aimed at helping the individual to learn or relearn their normal response pattern can be used. Patients with high cognitive levels are expected to more easily understand the guidelines being given to them, which therefore results in greater functional requirement, a factor that may explain the regular relationship we observed between DASH and MMSE in our study.

Another factor related to the recovery of muscle function is the time variable. A sufficient number of motor fibers should reach the target organ within a given period of time to achieve the desired function. ${ }^{4}$ Teboul et al. ${ }^{9}$ observed that patients operated on six months after injury had a $64.7 \%$ chance of a useful recovery of biceps function. On the other hand, patients operated on before that 6-month period following injury had an $86.7 \%$ chance of gaining useful elbow flexion. ${ }^{5}$ In a study conducted by Leechavengvongs et al., ${ }^{4}$ in which 32 patients were analyzed, the only patient who did not attain functional strength underwent the procedure 12 months following injury. ${ }^{3}$ Our study corroborates the results described in the literature: we found that patients undergoing the surgical procedure with periods of time greater than 12 months following injury did not attain elbow strength. This highlights the significant inverse correlation between time since trauma and recovery of muscle strength. It is worth mentioning one case of a patient operated on 15 months after injury who managed to recover functional strength grade 3 (BMRC).

The literature defines a 6 - to 12-month time interval as the appropriate time window for offering surgery to patients with upper trunk traction, avulsion injury. Although this may be considered ideal, Oberlin transfer can be attempted even in patients 12 to 24 months after injury, since the risk-benefit ratio in these patients can still be favorable. ${ }^{8}$

Taking into consideration this time interval and the patient's cognitive level, treatment planning can be better defined while respecting their individual characteristics and requirements to achieve the best functional outcome.

\section{CONCLUSION}

We found a positive correlation between the cognitive capacity and functional outcome of patients submitted to Oberlin surgery. The time elapsed between trauma and the surgical procedure has an inversely proportional correlation.

AUTHORS' CONTRIBUTIONS: Each individual author contributed individually and significantly to the development of this work. FASAF (0000-0001-59637573)*: Conception and design; Data Collection; Analysis and interpretation; Statistical analysis; Discussion of results; Writing the article; Final approval of the article. TGO (0000-0001-8249-2659)*: Data Collection; Analysis and interpretation; Discussion of results; Writing the article; Final approval of the article. WZS (0000-0002-9100-4749** Data Collection; Analysis and interpretation; Discussion of results; Writing the article; Final approval of the article. YAA (00000003-0752-5128)*: Conception and design; Discussion of results; Writing the article; Final approval of the article. ACC (0000-0002-5039-8884)*: Conception and design; Discussion of results; Writing the article; Final approval of the article. PMMBF (0000-0001-7081-987X)*: Conception and design; Discussion of results; Writing the article; Final approval of the article. *ORCID (Open Researcher and Contributor ID).

\section{REFERENCES}

1. Ali ZS, Heuer GG, Faught RW, Kaneriya SH, Sheikh UA, Syed IS, et al. Upper brachial plexus injury in adults: comparative effectiveness of different repair techniques. J Neurosurg. 2015;122(1):195-201.

2. Bertelli JA, Ghizoni MF. Reconstruction of C5 and C6 Brachial Plexus Avulsion injury by multiple nerve transfers: spinal accessory to suprascapular, ulnar fascicles to biceps branch, and triceps long or lateral head branch to axillary nerve. J Hand Surg Am. 2004;29(1):131-9.

3. Leechavengvongs S, Witoonchart K, Uerpairojkit C, Thuvasethakul P, Ketmalasiri W. Nerve transfer to biceps muscle using a part of the ulnar nerve in brachial plexus injury (upper arm type): a report of 32 cases. J Hand Surg Am. 1998;23(4):711-6.

4. Liverneaux PA, Diaz LC, Beaulieu JY, Durand S, Oberlin C. Preliminary results of double nerve transfer to restore elbow flexion in upper type brachial plexus palsies. Plast Reconstr Surg. 2006;117(3):915-9.

5. Mohammad-Reda A. Early post-operative results after repair of traumatic brachial plexus palsy. Turk Neurosurg. 2013;23(1):1-9.

6. Oberlin C, Beal D, Leechavengvongs S, Salon A, Dauge MC, Sarcy JJ. Nerve transfer to biceps muscle using a part of ulnar nerve for C5-C6 avulsion of the brachial plexus: anatomical study and report of four cases. J Hand Surg Am. 1994;19(2):232-7.

7. Rezende MR, Rabelo NTA, Silveira Júnior CC, Petersen PA, Paula EJL, Matta Jr R. Resultado da neurotização do nervo ulnar para o músculo bíceps braquial na lesão do plexo braquial. Acta Ortop Bras. 2012;20(6):317-23.

8. Sedain G, Sharma MS, Sharma BS, Mahapatra AK. Outcome After delayed oberlin transfer in brachial plexus injury. Neurosurgery. 2011;69(4):822-7.

9. Teboul F, Kakkar R, Ameur N, Beaulieu JY, Oberlin C. Transfer of Fascicles from the ulnar nerve to the nerve to the biceps in the treatment of upper brachial plexus palsy. J Bone Joint Surg Am. 2004;86-A(7):1485-90.
10. Tsai YJ, Su FC, Hsiao CK, Tu YK. Comparison of objective muscle strength in C5-C6 and C5-C7 brachial plexus injury patients after double nerve transfer. Microsurgery. 2015;35(2):107-14.

11. Maricq C, Jeunehomme M, Mouraux D, Rémy $P$, Brassinne $E$, Bahm J, et al. Objective evaluation of elbow flexion strength and fatigability after nerve transfer in adult traumatic upper brachial plexus injuries. Hand Surg. 2014;19(3):335-41.

12. Feng JT, Liu HQ, Hua XY, Gu YD, Xu JG, Xu WD. Brain functional network abnormality extends beyond the sensorimotor network in brachial plexus injury patients. Brain Imaging Behav. 2016;10(4):1198-205.

13. Boender ZJ, Ultee J, Hovius SRE. Cognitive capacity: no association with recovery of sensibility by Semmes Weinstein test score after peripheral nerve injury of the forearm. J Plastic Reconstr Aesthet Surg. 2010;63(2):354-9.

14. Rosén B, Lundborg G, Dahlin LB, Holmberg J, Karlson B. Nerve repair: correlation of restitution of functional sensibility with specific cognitive capacities. J Hand Surg Br. 1994;19(4):452-8

15. Orfale AG, Araújo PMP, Ferraz MB, Natour J. Translation into Brazilian Portuguese cultural adaptation and evaluation of the reliability of the Disabilities of the Arm Shoulder and Hand Questionnaire. Braz J Med Biol Res. 2005;38(2):293-302.

16. Brucki SMD, Nitrini R, Caramelli P, Bertolucci PHF, Okamoto IH. Sugestões para o uso do mini-exame do estado mental no Brasil. Arq Neuro-psiquiatr. 2003;61(3B):777-81.

17. Brown LE, Weir JP. ASEP Procedures recommendation I: accurate assessment of muscular strength and power. J Exerc Physiol. 2001;4(3):1-21.

18. MahmoudAliloo M, Bakhshipour A, Hashemi T, Roofigari AR, Hassan-Zadeh R. The correlation of cognitive capacity with recovery of hand sensibility after peripheral nerve injury of upper extremity. NeuroRehabilitation. 2011;29(4):373-9. 